\title{
Evaluating the use of blue phosphors in white LEDs: the case of $\mathrm{Sr}_{0.25} \mathrm{Ba}_{0.75} \mathrm{Si}_{2} \mathrm{O}_{2} \mathrm{~N}_{2}: \mathrm{Eu}^{2+}$
}

Jonas J Joos ${ }^{1,2}$, Jonas Botterman ${ }^{1,2}$ and Philippe F Smet ${ }^{1,2^{*}}$

\author{
* Correspondence: \\ philippe.smet@UGent.be \\ ${ }^{1}$ LumiLab, Department of Solid \\ State Sciences, Ghent University, \\ Krijgslaan 281-S1, 9000 Gent, \\ Belgium \\ ${ }^{2}$ Center for Nano and Biophotonics \\ (NB Photonics), Ghent University \\ Ghent, Belgium
}

\begin{abstract}
The luminescence properties of the blue emitting phosphor $\mathrm{Sr}_{0.25} \mathrm{Ba}_{0.75} \mathrm{Si}_{2} \mathrm{O}_{2} \mathrm{~N}_{2}: \mathrm{Eu}^{2+}$ are extensively investigated. This oxonitridosilicate phosphor features strong $4 f^{6} 5 d^{1}-4 f^{7}$ luminescence originating from the $\mathrm{Eu}^{2+}$ ion, with a narrow emission band peaking at $467 \mathrm{~nm}$ and a full width at half maximum of only $41 \mathrm{~nm}$. Thermal quenching of the blue luminescence only sets in above $450 \mathrm{~K}$, making this material an interesting candidate as LED conversion phosphor. The fast decay of the luminescence prevents the phosphor to be susceptible to saturation effects at high excitation fluxes. Furthermore it is proven to be chemically stable against moisture. The only drawback is the relatively low quantum efficiency of the synthesized powder, provisionally preventing this material to be used in applications. In addition, the phosphor features a weak yellow emission band, originating from small domains featuring a different crystal structure. It is shown that the majority of the powder grains only exhibit blue emission. Finally, the spectrum of a white LED, based on a UV pumping LED and three (oxy)nitride phosphors is simulated in order to assess the usefulness of blue phosphors in LEDs for lighting. Only a marginal improvement in terms of color quality can be achieved with a narrow banded phosphor, at the expense of a decrease in luminous efficacy and overall electrical to optical power efficiency.

PACS 70 - Condensed Matter: Electronic structure, Electrical, Magnetic, and

Optical Properties

PACS 42.70.-a Optical materials
\end{abstract}

Keywords: Oxonitridosilicate; Europium; Conversion phosphor; LED; Luminescence; Cathodoluminescence; Scanning electron microscopy; Color quality scale

\section{Background}

Light-emitting diodes or LEDs are steadily consolidating their share in the lighting and display market. Nevertheless, current technology is not yet fully established and improvements are still desirable, for both lighting and display applications.

For lighting applications, there is still a fair margin for improvement in terms of luminous efficacy and color rendering. The first phosphor converted LEDs (pc-LEDs), based on a blue $\operatorname{In}_{1-x} \mathrm{Ga}_{x} \mathrm{~N}$ pumping diode and a yellow (typically $\mathrm{Y}_{3} \mathrm{Al}_{5} \mathrm{O}_{12}: \mathrm{Ce}^{3+}[1,2]$ ) conversion phosphor, suffered from a low color rendering due to the lack of green and red light in the spectrum and of inherently high correlated color temperatures (CCT). This issue could to a great extend be solved by adding a red phosphor (for example $\mathrm{Ca}_{1-x} \mathrm{Sr}_{x} \mathrm{~S}: \mathrm{Eu}^{2+}[3]$ or $\left.\mathrm{Sr}_{2} \mathrm{Si}_{5} \mathrm{~N}_{8}: \mathrm{Eu}^{2+}[4,5]\right)$. While the low energy sector of the visible spectrum is then sufficiently covered by the phosphor blend, a void remains in the 
blue-cyan part of the spectrum, in between the narrow banded spectrum of the pumping LED and the emission of the phosphor(s). The first way to solve this consists of filling the gap by using a cyan phosphor with a small Stokes shift. The second option, which will be pursued in this paper, uses a violet or near UV pumping diode in combination with an additional blue phosphor.

To evaluate whether a luminescent material is suitable for use in phosphor converted LEDs, several requirements have to be fulfilled simultaneously. These are described in detail in [6] and comprise thermal stability of the luminescence, the absence of saturation effects at high excitation fluxes and chemical stability of the host material in combination with more obvious requirements such as excitability, a high conversion efficiency and desirable color point.

The $\mathrm{MSi}_{2} \mathrm{O}_{2} \mathrm{~N}_{2}: \mathrm{Eu}^{2+}(\mathrm{M}=\mathrm{Ca}, \mathrm{Sr}, \mathrm{Ba})$ system has already been the subject of extensive and detailed studies [7-14]. All three basic compounds (i.e. with only one type of alkaline earth metal) exhibit strong $4 \mathrm{f}^{6} 5 \mathrm{~d}^{1}-4 \mathrm{f}^{7}$ luminescence upon doping with divalent europium. While $\mathrm{BaSi}_{2} \mathrm{O}_{2} \mathrm{~N}_{2}: \mathrm{Eu}^{2+}$ features a greenish-blue narrow banded emission, $\mathrm{SrSi}_{2} \mathrm{O}_{2} \mathrm{~N}_{2}: \mathrm{Eu}^{2+}$ and $\mathrm{CaSi}_{2} \mathrm{O}_{2} \mathrm{~N}_{2}: \mathrm{Eu}^{2+}$ are characterized by significantly broader yellowish-green and yellow emission bands, respectively.

Structurally, the class of $\mathrm{MSi}_{2} \mathrm{O}_{2} \mathrm{~N}_{2}$ oxonitridosilicates is built from alternating layers of metal ions and layers of $\mathrm{SiON}_{3}$ tetrahedra in which the nitrogen atoms connect the silicon atoms, forming a structure with so-called dreier rings. Although this layered structure is similar for all members of the $\mathrm{MSi}_{2} \mathrm{O}_{2} \mathrm{~N}_{2}$ family, the basic compounds possess significantly different crystal structures, for example the orientation of the $\mathrm{O}$ atoms in the $\mathrm{SiON}_{3}$ tetrahedra. For more details about the crystal structures of the $\mathrm{MSi}_{2} \mathrm{O}_{2} \mathrm{~N}_{2}$ oxonitridosilicates, we refer to [15-17]. The structural differences between the basic compounds implicate that forming a solid solution by mixing of the metal ions is only possible up to a certain limit, above which a second phase will be formed during the synthesis [7]. Generally, a precise determination of the crystal structure is often difficult for these layered materials. In the next part, the already known luminescent properties of the $\mathrm{MSi}_{2} \mathrm{O}_{2} \mathrm{~N}_{2}: \mathrm{Eu}^{2+}$ family are shortly reviewed. Key structural and luminescent quantities are summarized in Table 1.

$\mathrm{BaSi}_{2} \mathrm{O}_{2} \mathrm{~N}_{2}: \mathrm{Eu}^{2+}$ is an efficient phosphor, even though it has the lowest quantum efficiency of the basic compounds (Table 1). It features a narrow emission band peaking at $495 \mathrm{~nm}$ (full width at half maximum (FWHM) of $32 \mathrm{~nm}$ ). Depending on the synthesis conditions, an appreciable afterglow and strong mechanoluminescence are observed, making it suitable for use as pressure sensor $[10,20,23]$.

Table 1 Structural and luminescence properties of europium doped $\mathrm{MSi}_{2} \mathrm{O}_{2} \mathrm{~N}_{2}$ phosphors

\begin{tabular}{|c|c|c|c|c|c|c|c|c|}
\hline Host material & $\begin{array}{l}\text { Space } \\
\text { group }\end{array}$ & $\begin{array}{l}\text { \# cation } \\
\text { sites }\end{array}$ & $\begin{array}{l}\lambda_{\max } \\
(\mathrm{RT})(\mathrm{nm})\end{array}$ & $\begin{array}{l}\text { FWHM } \\
\text { (RT) (nm) }\end{array}$ & $\begin{array}{l}\mathrm{QE}(\mathrm{RT}) \\
\text { int/ext }\end{array}$ & $\tau(\mu \mathrm{s})$ & $\mathrm{T}_{0.5}(\mathrm{~K})$ & Refs. \\
\hline $\mathrm{CaSi}_{2} \mathrm{O}_{2} \mathrm{~N}_{2}$ & $P 2_{1}$ & 6 & 555 & 106 & 76/- & 1.00 & 440 & {$[7,15]$} \\
\hline $\mathrm{SrSi}_{2} \mathrm{O}_{2} \mathrm{~N}_{2}$ (triclinic) & $P 1$ & 4 & 538 & 76 & $91 /-$ & 1.15 & 600 & {$[7,11,16]$} \\
\hline $\mathrm{SrSi}_{2} \mathrm{O}_{2} \mathrm{~N}_{2}$ (monoclinic) & $P 2_{1}$ & 4 & 532 & 75 & $-1-$ & - & - & [18] \\
\hline $\mathrm{Sr}_{0.25} \mathrm{Ba}_{0.75} \mathrm{Si}_{2} \mathrm{O}_{2} \mathrm{~N}_{2}$ (triclinic) & $P 1$ & 4 & 564 & 95 & $66 /-$ & - & - & [7] \\
\hline $\begin{array}{l}\mathrm{Sr}_{0.25} \mathrm{Ba}_{0.75} \mathrm{Si}_{2} \mathrm{O}_{2} \mathrm{~N}_{2} \\
\text { (orthorhombic) }\end{array}$ & $\mathrm{Pna}_{1}$ & 1 & 467 & 41 & $41 / 30$ & 0.35 & 545 & [19], this work \\
\hline $\mathrm{BaSi}_{2} \mathrm{O}_{2} \mathrm{~N}_{2}$ & $\mathrm{Cmc}_{1}$ & 1 & 495 & 32 & 71/- & 0.47 & 600 & {$[7,17,20]$} \\
\hline $\mathrm{EuSi}_{2} \mathrm{O}_{2} \mathrm{~N}_{2}$ & $P 1$ & 4 & 568 & 120 & $-1-$ & - & - & {$[21,22]$} \\
\hline
\end{tabular}

Structural and luminescence properties of europium doped $\mathrm{MSi}_{2} \mathrm{O}_{2} \mathrm{~N}_{2}$ phosphors. 
$\mathrm{SrSi}_{2} \mathrm{O}_{2} \mathrm{~N}_{2}: \mathrm{Eu}^{2+}$ is a very efficient phosphor with a reported internal quantum efficiency of up to $90 \%$ [11]. It also exhibits afterglow upon UV excitation [10]. The superior thermal properties make this phosphor a primary candidate as green-yellow conversion phosphor in white phosphor converted LEDs. Up to $50 \%$ of $\mathrm{Sr}^{2+}$ can be replace by $\mathrm{Ca}^{2+}$ to gently shift the emission color from yellow-green to yellow while keeping a single crystal phase [7]. Finally, $\mathrm{CaSi}_{2} \mathrm{O}_{2} \mathrm{~N}_{2}: \mathrm{Eu}^{2+}$ is characterized by a much worse thermal quenching behavior [7].

In Bachmann et al., the $\mathrm{Sr}_{1-x} \mathrm{Ba}_{x} \mathrm{Si}_{2} \mathrm{O}_{2} \mathrm{~N}_{2}: \mathrm{Eu}^{2+}$ solid solution is investigated for $x$ up to 0.75 [7]. By replacing $\mathrm{Sr}^{2+}$ by $\mathrm{Ba}^{2+}$ in the $\mathrm{SrSi}_{2} \mathrm{O}_{2} \mathrm{~N}_{2}: \mathrm{Eu}^{2+}$ phosphor, the color is surprisingly red shifted. This was explained by $\mathrm{Eu}^{2+}$ preferentially occupying $\mathrm{Sr}^{2+}$ sites in the lattice, while further substitution of $\mathrm{Sr}^{2+}$ by $\mathrm{Ba}^{2+}$ enlarges the experienced crystal field strength, due to compression of the coordination sphere of the remaining Sr sites. It is impossible to synthesize solid solutions between the yellow $(x=0.75)$ and blue-green $(x=1)$ phosphor $[7,12]$.

In 2012, Seibald et al. reported the remarkably blue luminescence of a $\mathrm{Sr}_{0.25} \mathrm{Ba}_{0.75} \mathrm{Si}_{2} \mathrm{O}_{2} \mathrm{~N}_{2}: \mathrm{Eu}^{2+}$ phosphor and its crystal structure [19]. From single-crystal diffraction, the "averaged" crystal structure was determined to be orthorhombic, while a more detailed investigation with HRTEM allowed to resolve the local cation ordering, resulting in a triclinic structure [19]. This is in contrast to the yellow phosphor with the same stoichiometry, which resembles the triclinic $\mathrm{SrSi}_{2} \mathrm{O}_{2} \mathrm{~N}_{2}$ crystal structure. The host material of this blue emitting material turned out to be composed of a $\mathrm{BaSi}_{2} \mathrm{O}_{2} \mathrm{~N}_{2}$ like structure. However, for this particular composition, the metal layers are corrugated, yielding different luminescent properties than $\mathrm{BaSi}_{2} \mathrm{O}_{2} \mathrm{~N}_{2}: \mathrm{Eu}^{2+}$ where the metal layers are parallel [19].

In another paper, in 2013, Seibald et al. reported the occurrence of an additional monoclinic $\mathrm{SrSi}_{2} \mathrm{O}_{2} \mathrm{~N}_{2}$ phase [18]. A single crystal could be isolated and structurally analyzed. The emission signal is slightly blue shifted compared with the common triclinic $\mathrm{SrSi}_{2} \mathrm{O}_{2} \mathrm{~N}_{2}$ phase. The structural difference between the two phases is the relative orientation of consecutive silicate layers. It was questioned whether it would be possible to synthesize a pure $\mathrm{SrSi}_{2} \mathrm{O}_{2} \mathrm{~N}_{2}$ phase without formation of the other one [18].

In this paper, a more thorough luminescence study is conducted on the blue oxonitridosilicate phosphor $\mathrm{Sr}_{0.25} \mathrm{Ba}_{0.75} \mathrm{Si}_{2} \mathrm{O}_{2} \mathrm{~N}_{2}: \mathrm{Eu}^{2+}$, which was reported in 2012 but not yet fully characterized until this moment. Possible applications for this phosphor are evaluated, after which the discussion is generalized to evaluate the usefulness of blue phosphors in LED lighting technology.

\section{Methods}

$\mathrm{Sr}_{0.25} \mathrm{Ba}_{0.75} \mathrm{Si}_{2} \mathrm{O}_{2} \mathrm{~N}_{2}: \mathrm{Eu}^{2+}$ (with an europium concentration of 1 molar \%) luminescent powders were synthesized by a solid state reaction in a tube furnace at high temperature. During all heat treatments, the powder mixtures were kept in a controlled atmosphere of forming gas $\left(90 \% \mathrm{~N}_{2}, 10 \% \mathrm{H}_{2}\right.$ mixture) and put inside zirconia crucibles. Two different synthesis methods were carried out:

1. In one step, with $\mathrm{SrCO}_{3}$ (Alfa Aesar, 99.99\%), $\mathrm{BaCO}_{3}$ (Alfa Aesar, 99.95\%), $\mathrm{Si}_{3} \mathrm{~N}_{4}$ ( $\alpha$-phase, Alfa Aesar, 99.9\%) and $\mathrm{EuF}_{3}$ (Alfa Aesar, 99.5\%) as starting materials. After dry ball mixing, the powder mixture was heat treated at $1400^{\circ} \mathrm{C}$ for 4 hours (heating rate of $4.7^{\circ} \mathrm{C} / \mathrm{min}$ ). 
2. In two steps. First $\left(\mathrm{Sr}_{0.25} \mathrm{Ba}_{0.75}\right)_{2} \mathrm{SiO}_{4}: \mathrm{Eu}$ is prepared from $\mathrm{SrCO}_{3}, \mathrm{BaCO}_{3}, \mathrm{SiO}_{2}$ (Alfa Aesar, $99.9 \%$ ) and $\mathrm{EuF}_{3}$ at $1250^{\circ} \mathrm{C}$ for 3 hours (heating rate of $4.7^{\circ} \mathrm{C} / \mathrm{min}$ ). Second, $\mathrm{Si}_{3} \mathrm{~N}_{4}$ was dry ball mixed with the obtained orthosilicate and heat treated at $1400^{\circ} \mathrm{C}$ for 4 hours (heating rate of $4.7^{\circ} \mathrm{C} / \mathrm{min}$ ). This is the synthesis recipe described in [19].

After the heat treatments, the powders were allowed to cool naturally and were lightly ground.

Powder X-ray diffraction (XRD) measurements were performed on a Siemens D5000 diffractometer $(40 \mathrm{kV}, 40 \mathrm{~mA})$ using $\mathrm{CuK} \alpha_{1}$ radiation.

Photoluminescence emission and excitation spectra were measured with an Edinburgh FS920 fluorescence spectrometer. Measurements as a function of temperature were performed using an Oxford Optistat CF cryostat.

Decay profiles were measured using a pulsed nitrogen laser (wavelength $337 \mathrm{~nm}$ ) as an excitation source in combination with an Andor intensified CCD.

SEM-EDX-CL measurements were performed with an Hitachi S-3400 N scanning electron microscope (SEM), equipped with a Thermo Scientific Noran 7 energy dispersive X-ray detector (EDX). Furthermore, cathodoluminescence (CL) was collected with an optical fiber and analyzed by a CCD camera (Princeton Instruments ProEM 1600²), attached to a spectrograph (Princeton Instruments Acton SP2358). An integrating sphere (LabSphere GPS-SL series) was used to measure the internal and external quantum efficiency (QE) of the phosphor powders upon LED excitation (peak wavelength of $370 \mathrm{~nm}$ ). $\mathrm{Al}_{2} \mathrm{O}_{3}$ was used as a white reflecting standard.

Accelerated aging tests were done inside a Memmert HCP108 humidity chamber, with a constant temperature and relative humidity $(\mathrm{RH})$ of $75^{\circ} \mathrm{C}$ and $75 \% \mathrm{RH}$. The photoluminescence was monitored in situ by excitation with a $370 \mathrm{~nm}$ LED.

\section{Results and discussion}

\section{Synthesis and XRD}

For the synthesis of the blue emitting $\mathrm{Sr}_{0.25} \mathrm{Ba}_{0.75} \mathrm{Si}_{2} \mathrm{O}_{2} \mathrm{~N}_{2}: \mathrm{Eu}^{2+}$ phosphor, Seibald et al. used a dual step solid state synthesis based on the orthosilicate $\left(\mathrm{Sr}_{0.25} \mathrm{Ba}_{0.75}\right)_{2} \mathrm{SiO}_{4}: \mathrm{Eu}^{2+}$ phosphor as intermediate product [19,24]. In this work, it could be confirmed that this synthesis method indeed yields the described blue phosphor. However, the same phosphor could also be synthesized in a faster one-step way, similar to the method described in [7]:

$$
3 \mathrm{MCO}_{3}+2 \mathrm{Si}_{3} \mathrm{~N}_{4} \rightarrow 3 \mathrm{MSi}_{2} \mathrm{O}_{2} \mathrm{~N}_{2}+\mathrm{N}_{2}+3 \mathrm{CO}
$$

After the heat treatment, visual inspection under UV illumination learns that the bulk of the obtained phosphor powder has the desired blue color. On top of the blue powder, a thin, green emitting layer is formed. For further investigation, this green emitting top layer was removed and kept apart. This green emitting layer was also formed during the dual step synthesis. X-ray diffraction (XRD) and photoluminescence (PL) measurements (see further) were addressed to verify that the result of both syntheses are indeed identical. The powder prepared with the one step synthesis was selected for further investigation.

It was reported that the addition of small amounts of $\mathrm{NH}_{4} \mathrm{Cl}$ as fluxing agent during the temperature treatment improves the formation and crystallization of the $\mathrm{SrSi}_{2} \mathrm{O}_{2} \mathrm{~N}_{2}: \mathrm{Eu}^{2+}$ phosphor [25]. The influence of $\mathrm{NH}_{4} \mathrm{Cl}$ (2 weight \% of the final mass) on the formation of the blue phosphor was investigated. It turns out that the fluxing agent rather stimulates 
the formation of an undesired yellow emission band next to the blue emission band. Therefore, $\mathrm{NH}_{4} \mathrm{Cl}$ was omitted from further syntheses.

To specify the composition of the powders, X-ray diffraction (XRD) measurements were performed. The results are summarized in Figures 1 and 2. The XRD pattern for the blue emitting bulk powder (Figure 1) shows a reasonably good comparison with the calculated one from the structure reported in [19]. The XRD measurement indicates that texture effects are present. However, the locations of the reflections are in correspondence with those of the reference pattern, indicating that the desired $\mathrm{Sr}_{0.25} \mathrm{Ba}_{0.75} \mathrm{Si}_{2} \mathrm{O}_{2} \mathrm{~N}_{2}: \mathrm{Eu}^{2+}$ phosphor is obtained. Additionally, some extra reflections appear around $2 \theta=30^{\circ}$. These might be originating from small amounts of $\mathrm{BaSi}_{6} \mathrm{~N}_{8} \mathrm{O}$ that formed during the high temperature synthesis. Since $\mathrm{BaSi}_{6} \mathrm{~N}_{8} \mathrm{O}: \mathrm{Eu}^{2+}$ is reported to show fluorescence in the blue-green spectral region (emission band peaking at $503 \mathrm{~nm}$, FWHM of $102 \mathrm{~nm}$ [29]), this might compromise the characterization of the $\mathrm{Sr}_{0.25} \mathrm{Ba}_{0.75} \mathrm{Si}_{2} \mathrm{O}_{2} \mathrm{~N}_{2}$ : $\mathrm{Eu}^{2+}$ phosphor.

From the XRD measurement of the green emitting top layer, it can be derived that it is mainly composed of $\mathrm{Ba}_{3} \mathrm{Si}_{6} \mathrm{O}_{9} \mathrm{~N}_{4}: \mathrm{Eu}^{2+}$ (filled circles, Figure 2) and $\mathrm{Ba}_{3} \mathrm{Si}_{6} \mathrm{O}_{12} \mathrm{~N}_{2}: \mathrm{Eu}^{2+}$ (open squares, Figure 2). The locations of the experimental reflections are slightly shifted to higher $2 \theta$ values, which is explained by the incorporation of some $\mathrm{Sr}^{2+}$ in the crystal structure, decreasing the effective lattice parameters. $\mathrm{Ba}_{3} \mathrm{Si}_{6} \mathrm{O}_{12} \mathrm{~N}_{2}: \mathrm{Eu}^{2+}$ is known to give green emission, explaining the green color of the top layer under UV excitation $[27,30]$. The blue luminescence of $\mathrm{Ba}_{3} \mathrm{Si}_{6} \mathrm{O}_{9} \mathrm{~N}_{4}: \mathrm{Eu}^{2+}$ is thermally quenched at room temperature [30]. Note that both impurities have the same $(\mathrm{Sr}, \mathrm{Ba}): \mathrm{Si}$ ratio of 1:2, as in the intended stoichiometry. The main difference is the larger oxygen to nitrogen ratio, which is probably due to oxygen traces during the synthesis process.

\section{Photoluminescence}

The photoluminescence of the $\mathrm{Sr}_{0.25} \mathrm{Ba}_{0.75} \mathrm{Si}_{2} \mathrm{O}_{2} \mathrm{~N}_{2}: \mathrm{Eu}^{2+}$ phosphor features broadband emission and excitation spectra (Figure 3), characteristic for the $4 \mathrm{f}^{7}-4 \mathrm{f}^{6} 5 \mathrm{~d}^{1}$ transitions within the $\mathrm{Eu}^{2+}$ ion. The emission spectrum peaks at room temperature at $467 \mathrm{~nm}$ and has a full width at half maximum (FWHM) of $41 \mathrm{~nm}$.

In the emission spectrum, a second contribution in the yellow range around $560 \mathrm{~nm}$, is clearly visible. The origin of this second emission band might be the occurrence of a $\mathrm{Sr}_{1-\mathrm{x}} \mathrm{Ba}_{\mathrm{x}} \mathrm{Si}_{2} \mathrm{O}_{2} \mathrm{~N}_{2}: \mathrm{Eu}^{2+}$ phase with a different structure than the intended blue phosphor, which has "averaged" an orthorhombic structure. In their paper, Bachmann et al. report

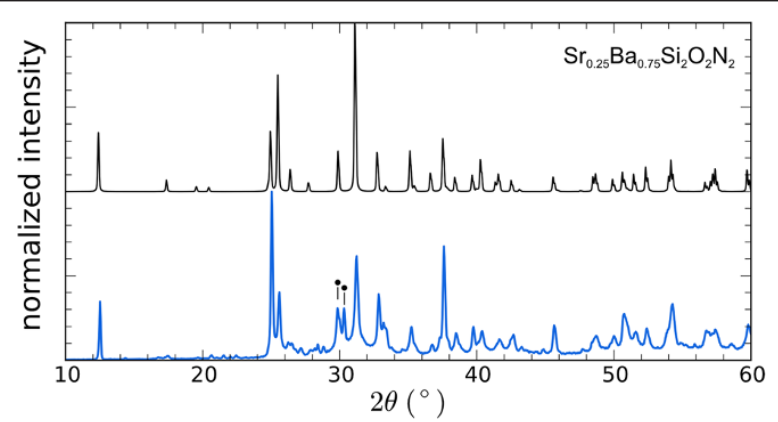

Figure 1 XRD measurement of the blue phosphor. XRD measurement of the prepared $\mathrm{Sr}_{0.25} \mathrm{Ba}_{0.75} \mathrm{Si}_{2} \mathrm{O}_{2} \mathrm{~N}_{2}: \mathrm{Eu}^{2+}$ powder (bottom), compared with the calculated pattern for $\mathrm{Sr}_{0.25} \mathrm{Ba}_{0.75} \mathrm{Si}_{2} \mathrm{O}_{2} \mathrm{~N}_{2}$ (top) [19]. The black circles indicate reflections, possibly originating from $\mathrm{BaSi}_{6} \mathrm{~N}_{8} \mathrm{O}[26]$. 


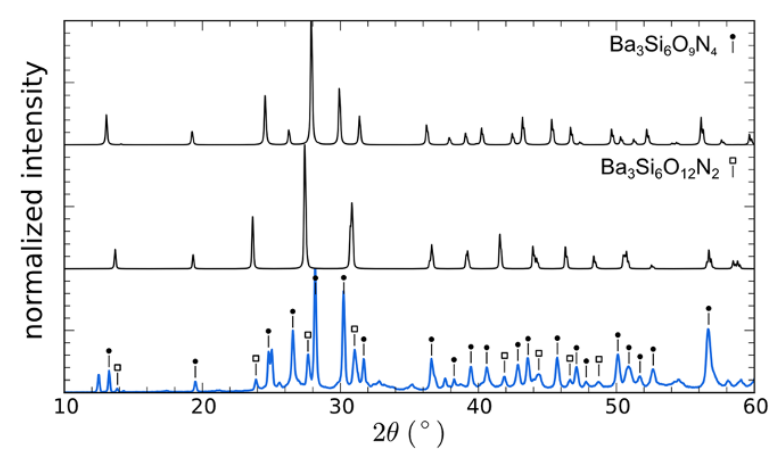

Figure 2 XRD measurement of the top layer. XRD measurement of the prepared green emitting top layer (bottom), compared with the calculated pattern for $\mathrm{Ba}_{3} \mathrm{Si}_{6} \mathrm{O}_{12} \mathrm{~N}_{2}$ (middle) and $\mathrm{Ba}_{3} \mathrm{Si}_{6} \mathrm{O}_{9} \mathrm{~N}_{4}$ (top) $[27,28]$.

a $\mathrm{Sr}_{0.25} \mathrm{Ba}_{0.75} \mathrm{Si}_{2} \mathrm{O}_{2} \mathrm{~N}_{2}: \mathrm{Eu}^{2+}$ phase with the triclinic $\mathrm{SrSi}_{2} \mathrm{O}_{2} \mathrm{~N}_{2}$ structure, emitting a broadband spectrum, peaking at $564 \mathrm{~nm}[7,31]$. It is not unlikely that this is the phase responsible for the weak yellow emission band. If this impurity phase indeed has the $\mathrm{SrSi}_{2} \mathrm{O}_{2} \mathrm{~N}_{2}$ structure, it is not surprising that the addition of $\mathrm{NH}_{4} \mathrm{Cl}$ flux during the heat treatment stimulates the formation of it [25]. This yellow emission band also occurred in the spectrum from the original paper reporting the blue phosphor [19].

Since the XRD measurements suggest the occurrence of small quantities of $\mathrm{BaSi}_{6} \mathrm{~N}_{8} \mathrm{O}: \mathrm{Eu}^{2+}$, it is important to verify whether this has an influence on the photoluminescence of the powders. The emission spectrum of $\mathrm{BaSi}_{6} \mathrm{~N}_{8} \mathrm{O}: \mathrm{Eu}^{2+}$ features a broad band $($ FWHM $=102 \mathrm{~nm})$, centered at $503 \mathrm{~nm}$ and can be excited between $200 \mathrm{~nm}$ and $400 \mathrm{~nm}$ [29], although no values for the QE have been reported. To verify the occurrence of this blue-green phosphor, two emission scans of the prepared powder were compared, one at $310 \mathrm{~nm}$ excitation and one at $410 \mathrm{~nm}$ excitation, the former chosen in the maximum of the excitation band of $\mathrm{BaSi}_{6} \mathrm{~N}_{8} \mathrm{O}: \mathrm{Eu}^{2+}$, the latter chosen outside the excitation band of $\mathrm{BaSi}_{6} \mathrm{~N}_{8} \mathrm{O}: \mathrm{Eu}^{2+}$. Since no observable differences between the two scans were noticed, it can be concluded that the light-emitting $\mathrm{BaSi}_{6} \mathrm{~N}_{8} \mathrm{O}: \mathrm{Eu}^{2+}$ phase, as described by R.-J. Xie et al., is not observed in the prepared powder. This has therefore no influence on the characterization of the luminescence of the $\mathrm{Sr}_{0.25} \mathrm{Ba}_{0.75} \mathrm{Si}_{2} \mathrm{O}_{2} \mathrm{~N}_{2}: \mathrm{Eu}^{2+}$ powders apart for a possibly negative influence on the overall quantum efficiency of the phosphor.

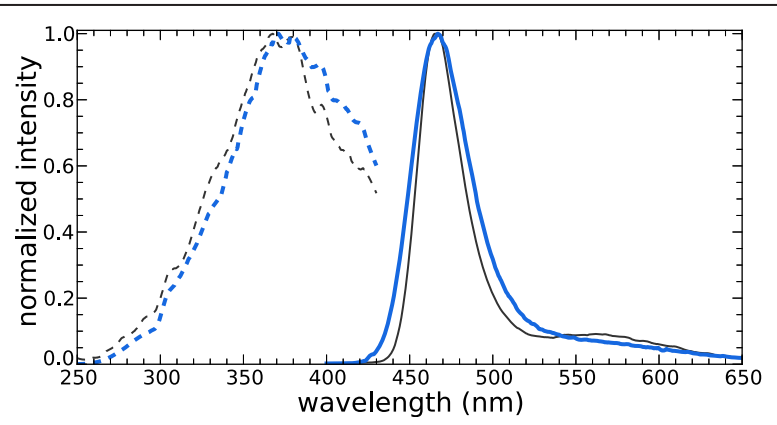

Figure 3 Photoluminescence spectra. Photoluminescence emission (excitation at $370 \mathrm{~nm}$, solid lines) and excitation (emission at $466 \mathrm{~nm}$, dashed lines) spectra of $\mathrm{Sr}_{0.25} \mathrm{Ba}_{0.75} \mathrm{Si}_{2} \mathrm{O}_{2} \mathrm{~N}_{2}: \mathrm{Eu}^{2+}$, measured at room temperature (blue, thick lines) and at $10 \mathrm{~K}$ (black, thin lines). 
The color point (CIE $x$, CIE $y$ ) of the complete emission spectrum (i.e. blue and yellow band) at room temperature is $(0.165,0.165)$. If the blue component would be the only feature of the emission spectrum, the color point is estimated at $(0.129,0.067)$. Clearly, a small amount of the impurity phase shifts the color point towards the white region of the chromaticity diagram (see Figure 4).

The internal and external quantum efficiency $(\mathrm{QE})$ of the photoluminescence were measured upon excitation with a $370 \mathrm{~nm}$ LED. The external QE $\eta_{\mathrm{ext}}$ is the ratio of emitted photons by the number of incident photons, while the internal QE $\eta_{\text {int }}$ considers only the absorbed photons:

$$
\eta_{\mathrm{ext}}=\frac{N_{\mathrm{em}}}{N_{\mathrm{inc}}} \quad \eta_{\mathrm{int}}=\frac{N_{\mathrm{em}}}{N_{\mathrm{abs}}} \quad \eta_{\mathrm{ext}}=A \eta_{\mathrm{int}}
$$

Herein, $N_{\text {inc }}, N_{\text {abs }}$ and $N_{\text {em }}$ are the number of incident, absorbed and emitted photons respectively. $A$ is the absorbed fraction. For the $\mathrm{Sr}_{0.25} \mathrm{Ba}_{0.75} \mathrm{Si}_{2} \mathrm{O}_{2} \mathrm{~N}_{2}: \mathrm{Eu}^{2+}$ phosphor, values of $\eta_{\text {ext }}=30 \%$ and $\eta_{\text {int }}=41 \%$ were obtained. This is significantly lower than the internal quantum efficiencies of benchmark phosphors (typically $\eta_{\text {int }} \approx 90 \%[11,32]$ ). The grey shade in the body color of the powder already hinted towards an insufficient QE. If impurity phases which do not emit light (potentially $\mathrm{BaSi}_{6} \mathrm{~N}_{8} \mathrm{O}$ ) are present in the powders, the measured QE will be lower than the intrinsic QE of the $\mathrm{Sr}_{0.25} \mathrm{Ba}_{0.75} \mathrm{Si}_{2} \mathrm{O}_{2} \mathrm{~N}_{2}: \mathrm{Eu}^{2+}$ phosphor. However, a sound optimization of the synthesis process (e.g. finding a suitable fluxing agent) might improve the quantum efficiency considerably because there does not seem to be a fundamental reason why the $\mathrm{Sr}_{0.25} \mathrm{Ba}_{0.75} \mathrm{Si}_{2} \mathrm{O}_{2} \mathrm{~N}_{2}: \mathrm{Eu}^{2+}$ phosphor should have a lower QE than comparable phosphors such as $\mathrm{BaSi}_{2} \mathrm{O}_{2} \mathrm{~N}_{2}: \mathrm{Eu}^{2+}$ or $\mathrm{SrSi}_{2} \mathrm{O}_{2} \mathrm{~N}_{2}: \mathrm{Eu}^{2+}$.

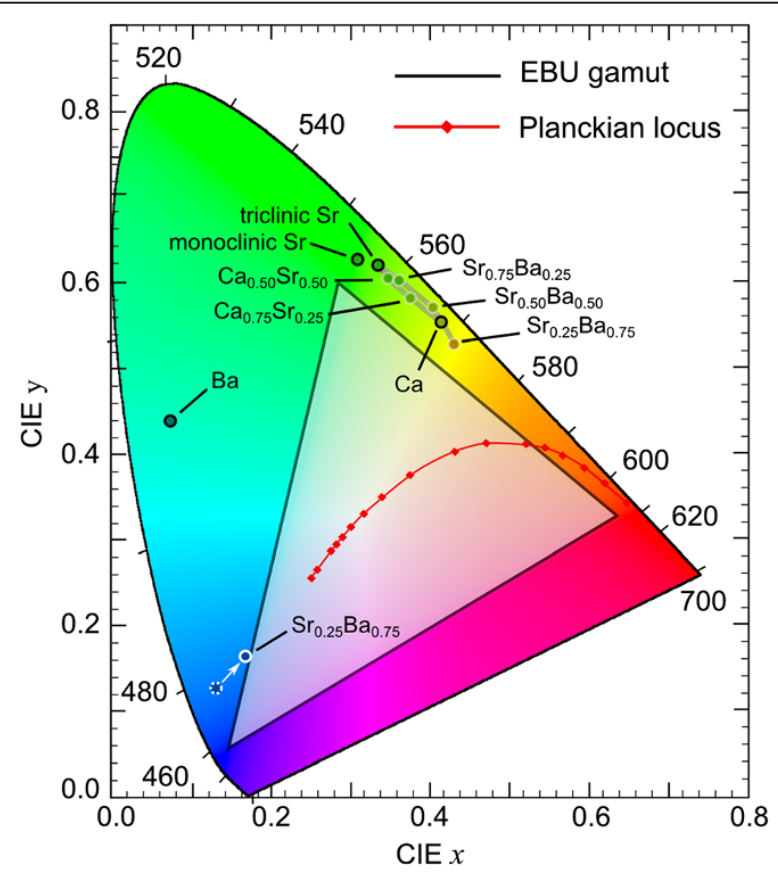

Figure 4 Chromaticity diagram with $\mathrm{MSi}_{2} \mathrm{O}_{2} \mathbf{N}_{2}: \mathrm{Eu}^{2+}$ phosphors. CIE 1931 chromaticity diagram with the color points of the $\mathrm{MSi}_{2} \mathrm{O}_{2} \mathrm{~N}_{2}: \mathrm{Eu}^{2+}$ family members. The white arrow indicates the color shift of the saturated blue $\mathrm{Sr}_{0.25} \mathrm{Ba}_{0.75} \mathrm{Si}_{2} \mathrm{O}_{2} \mathrm{~N}_{2}: \mathrm{Eu}^{2+}$ phosphor to the white due to the yellow emitting impurity phase. Color points of other phosphors from [7]. 


\section{SEM-EDX-CL}

From the photoluminescence measurements, it is clear that not a phase pure material is obtained. Combining cathodoluminescence (CL) and energy dispersive X-ray spectroscopy (EDX) inside a scanning electron microscope (SEM) should help to get a better grasp of the different phases that occur in the phosphor powder and their luminescence [33].

The morphology of the prepared powders consists of agglomerated, rod to plate-like particles, typically 10 to $20 \mu \mathrm{m}$ in length (Figure 5). This rather uncommon morphology seems not incompatible with the layered crystal structure of the host material. The EDX maps reveal a rather homogeneous composition, taking the influence of the sample morphology on the X-ray detection efficiency for the different elements into account.

At a few places, a higher than average silicon content could be found, although it could not be linked to a specific chemical composition, nor was it reflected in the CL spectra. These Si-rich areas are possibly related to the $\mathrm{BaSi}_{6} \mathrm{~N}_{8} \mathrm{O}$ phase which might be present in the powder. SEM-CL confirms the result from the PL measurement that there is no light emission originating from this phase. No results from thermal quenching or quantum efficiency measurements of the $\mathrm{BaSi}_{6} \mathrm{~N}_{8} \mathrm{O}: \mathrm{Eu}^{2+}$ phosphor are reported in literature. Furthermore, given the peculiar high Stokes shift of this material $(1.14 \mathrm{eV}$ or $9200 \mathrm{~cm}^{-1}$ ) and width of the emission band (estimated about $0.5 \mathrm{eV}$ or $4033 \mathrm{~cm}^{-1}$ ), one can doubt whether the reported luminescence is originating from a "normal" $\mathrm{Eu}^{2+}$ activated phosphor $[29,34,35]$.

The studied area, indicated by the blue rectangle in Figure 5, was divided into 256 by 192 pixels and in each pixel a full cathodoluminescence ( $E=15 \mathrm{keV})$ emission spectrum was recorded. Then for each spectrum, key luminescence parameters, such as the band width (FWHM) and the peak emission wavelength $\left(\lambda_{\max }\right)$ were determined. Figure 5 clearly shows that all studied particles have an emission peaking between 465

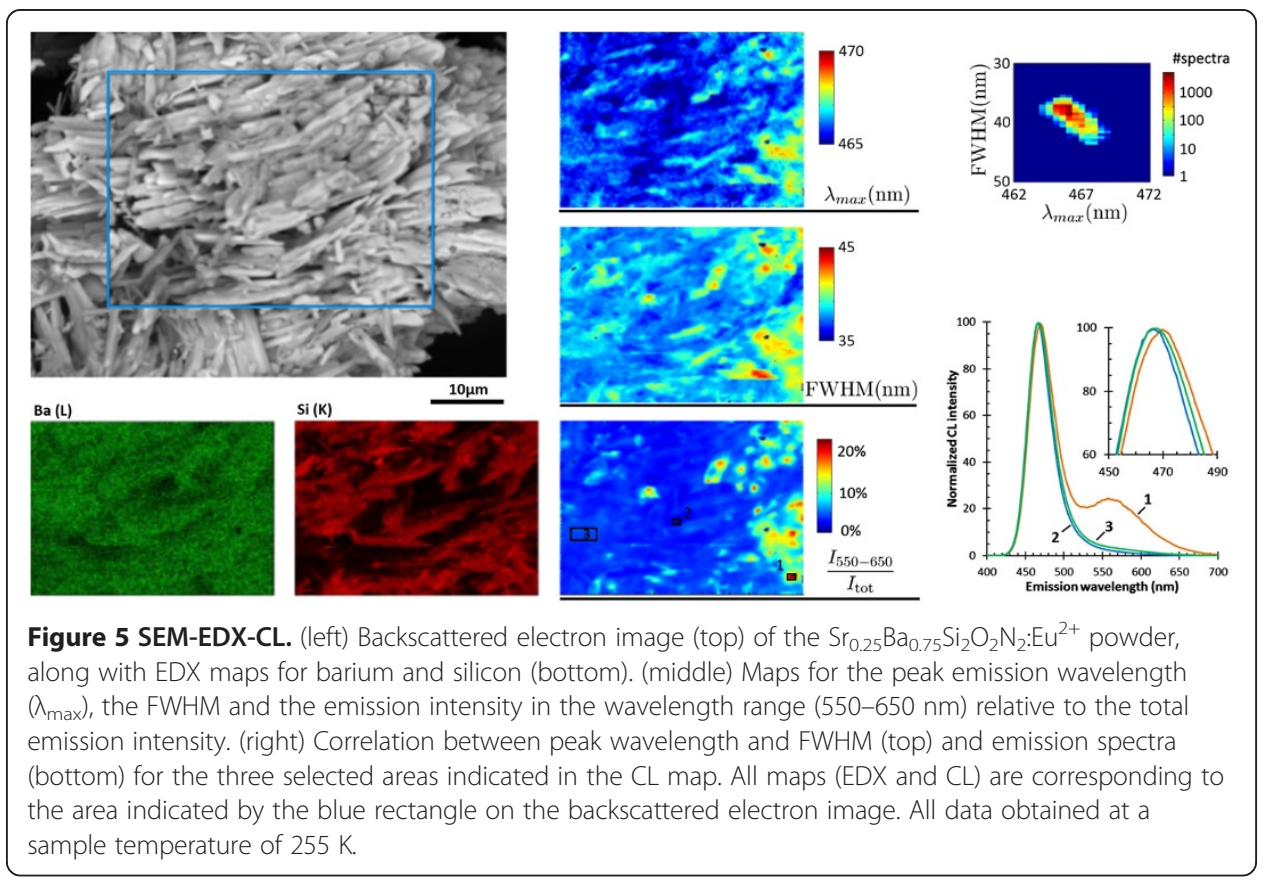


and $468 \mathrm{~nm}$, while the FWHM ranges between 37 and $43 \mathrm{~nm}$. This effect is larger than the mere consequence of the use of wavelength units. Averaging out over all pixels, a CL emission spectrum is obtained which is similar to the PL emission spectrum. Although the emission is very homogeneous over the studied area, there appears to be some correlation between $\lambda_{\max }$ and the FWHM, as longer peak emission wavelengths tend to coincide with wider emission bands (Figure 5), which could be due to local variations in composition (e.g. Eu concentration or $\mathrm{Sr}$ :Ba ratio).

The SEM-CL study also allows to probe the origin of the yellow emission band, peaking at $558 \mathrm{~nm}$, when preparing $\mathrm{Sr}_{0.25} \mathrm{Ba}_{0.75} \mathrm{Si}_{2} \mathrm{O}_{2} \mathrm{~N}_{2}: \mathrm{Eu}^{2+}$. Note that this emission band is found both in [19] and in this work. The yellow emission amounts to no more than $20 \%$ of the total emission intensity, and certainly no areas with pure yellow emission (i.e. in the absence of the blue emission band) could be found, which would be the case for a separately formed impurity phase. For these areas with a larger fraction of long wavelength emission, no deviation in stoichiometry could be found by means of SEM-EDX. This is no surprise since it was shown by Seibald et al. by a combination of TEM/ HRTEM/TEM-EDX that a domain structure is present at a nanometer length scale, impossible to resolve with SEM-EDX. The yellow emission is originating from domains with a Sr-richer content, composed of the $\mathrm{SrSi}_{2} \mathrm{O}_{2} \mathrm{~N}_{2}$ structure [14,19].

The SEM-CL study shows that yellow emission is always accompanied by the blue emission, within the same phosphor particles, supporting the conclusion by Seibald et al. that the yellow emission is due to intergrowth on the nanoscale. Nevertheless, the main fraction of the studied phosphor particles shows only the blue emission band, which offers the promise to prepare a purely blue emitting phosphor, without the additional yellow emission band from the Sr-rich domains. Regardless the impossibility of a SEM to resolve the nanoscopic domain structure, this clearly illustrates that the majority of the micrometer sized grains exhibit only the blue luminescence. Therefore, the submicron resolution of CL in a SEM offers a fast and elegant way to probe the luminescence behavior at the single particle level, by being complementary to the aforementioned TEM study at the nanoscale [36].

\section{Thermal quenching}

In Figure 6, the integrated emission intensity is displayed as a function of temperature. Thermal quenching is starting around $450 \mathrm{~K}$ and the temperature where the emission

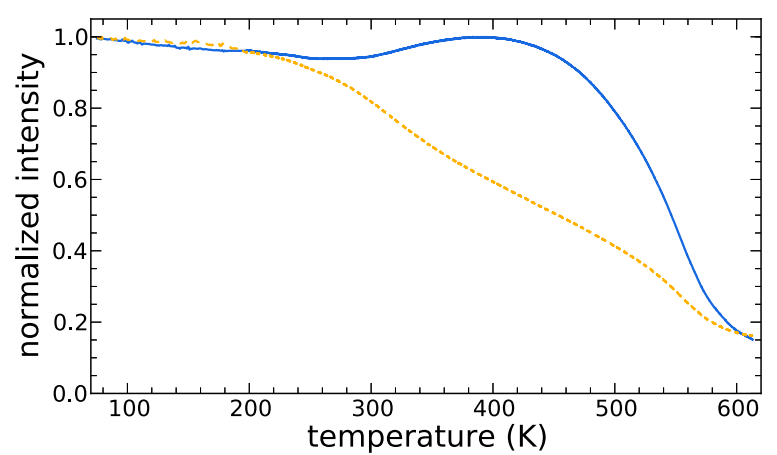

Figure 6 Thermal quenching. Integrated emission intensity of the blue (solid line) and yellow (dotted line) emission band as a function of temperature. Measured upon excitation with a $370 \mathrm{~nm}$ LED. 
intensity is halved with respect to low temperature $\left(T_{0.5}\right)$ is $545 \mathrm{~K}$. This means that this phosphor can safely be used in typical lighting applications, where the phosphor's temperature will remain below $450 \mathrm{~K}$. The thermal quenching behavior of the yellow component $\left(T_{0.5}=454 \mathrm{~K}\right)$ is worse though. In Table 2, some parameters describing the emission of $\mathrm{Sr}_{0.25} \mathrm{Ba}_{0.75} \mathrm{Si}_{2} \mathrm{O}_{2} \mathrm{~N}_{2}: \mathrm{Eu}^{2+}$ are given as a function of temperature. Not only the intensity of the blue luminescence stays constant in the relevant temperature range, also the color point remains stable, which is important from an application point of view. This is due to two opposite effects, namely the slightly broadening of the blue emission band and the quenching of the yellow one, which tend to cancel out to a large extent when the color point is calculated.

\section{Decay of luminescence}

The decay of the blue emission band was measured at room temperature. The decay profile is displayed in Figure 7. This profile could be fitted with a sum of two exponential functions:

$$
I(t)=I_{1} \mathrm{e}^{-t / \tau_{1}}+I_{2} \mathrm{e}^{-t / \tau_{2}}
$$

The obtained decay times are $461 \mathrm{~ns}$ and $219 \mathrm{~ns}$, with contributions of $66 \%$ and $34 \%$, respectively, to the total decay. The fractions were calculated as:

$$
f_{i}=\frac{\int I_{i} \mathrm{e}^{-t / \tau_{i}} \mathrm{~d} t}{\int I(t) \mathrm{d} t}=\frac{I_{i} \tau_{i}}{I_{1} \tau_{1}+I_{2} \tau_{2}} \quad(i=1,2)
$$

Both components are in the expected range for lifetimes of the $4 f^{6} 5 \mathrm{~d}^{1}$ excited state in the case of blue emission. This is slightly faster than the luminescent lifetime of $\mathrm{Eu}^{2+}$ in $\mathrm{BaSi}_{2} \mathrm{O}_{2} \mathrm{~N}_{2}$ (Table 1). This lies within expectations because the luminescence lifetime shortens when the emission color is blue shifted on condition that the refractive index does not change [37]. The origin of the faster decay component, presumably related to a non-radiative decay path, could not yet be clarified.

Because of the fast decay of the $4 \mathrm{f}^{6} 5 \mathrm{~d}^{1}$ excited state of $\mathrm{Eu}^{2+}$ in this host lattice, it is expected that high excitation fluxes can be used without sublinear response, as is the case in some applications [38].

\section{Chemical stability}

The chemical stability of the oxynitride phosphor was inspected by monitoring the in situ photoluminescence (excitation with a $370 \mathrm{~nm}$ LED) during an accelerated aging

Table 2 Features of the emission spectrum of $\mathrm{Sr}_{0.25} \mathrm{Ba}_{0.75} \mathrm{Si}_{2} \mathrm{O}_{2} \mathrm{~N}_{2}: \mathrm{Eu}^{2+}$ as a function of temperature

\begin{tabular}{llllll}
\hline $\boldsymbol{T}(\mathrm{K})$ & $\boldsymbol{\lambda}_{\max }(\mathrm{nm})$ & FWHM $(\mathrm{nm})$ & $\boldsymbol{I}(\boldsymbol{T}) /(\mathbf{3 0 0} \mathrm{K})$ & $(\mathrm{CIE} \boldsymbol{x}, \mathrm{CIE} \boldsymbol{y})$ & $\boldsymbol{d}_{\mathbf{u}^{\prime} \mathbf{v}^{\prime}}(\boldsymbol{T}, \mathbf{3 0 0} \mathrm{K})$ \\
\hline $\mathbf{3 0 0}$ & 467.4 & 41 & 1.00 & $(0.165,0.165)$ & 0.0000 \\
\hline $\mathbf{3 5 0}$ & 467.0 & 43 & 1.04 & $(0.164,0.164)$ & 0.0002 \\
\hline $\mathbf{4 0 0}$ & 466.6 & 49 & 1.06 & $(0.164,0.165)$ & 0.0008 \\
\hline
\end{tabular}

Features of the emission spectrum of $\mathrm{Sr}_{0.25} \mathrm{Ba}_{0.75} \mathrm{Si}_{2} \mathrm{O}_{2} \mathrm{~N}_{2}: \mathrm{Eu}^{2+}$ as a function of temperature, maximum $\left(\lambda_{\max }\right)$ and $\mathrm{FWHM}$ of the emission band, relative intensity of the blue emission band with respect to $300 \mathrm{~K}$, color point of the complete emission spectrum (blue and yellow component) and corresponding color shift in CIE L $\mathrm{u}^{\prime} \mathrm{v}^{\prime}$ color space. 


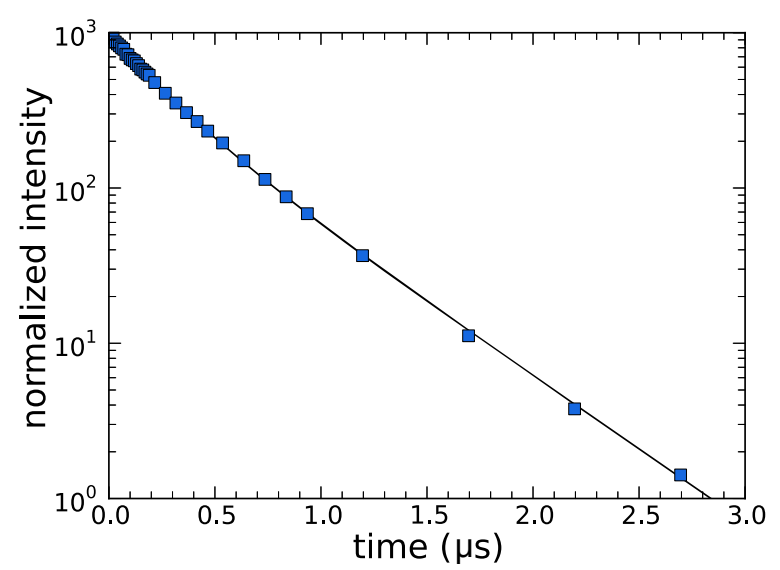

Figure 7 Decay profile. Decay profile of the blue emission band at $300 \mathrm{~K}$. Measured with a $337 \mathrm{~nm}$ pulsed laser as excitation source (blue diamonds). Fit with the sum of two exponential functions (black line).

test inside a humidity chamber $\left(75^{\circ} \mathrm{C}, 75 \%\right.$ relative humidity). In a timescale of 200 hours, no significant decrease of the luminescence could be measured for both the blue and yellow components (not shown).

\section{Blue phosphor for increased color rendering?}

Almost all current white pc-LEDs are composed of a blue pumping LED (peaking typically at 455 to $460 \mathrm{~nm}$ and $20 \mathrm{~nm}$ FWHM) and a yellow phosphor or green-red phosphor blend. As it was suggested that the blue phosphor under study can be applied in pc-LEDs with high color rendering index (CRI) [19], a simulation is conducted in order to estimate the increase in color rendering that can be achieved by using an additional blue phosphor [39].

In the simulations, a white LED with a correlated color temperature (CCT) of $4000 \mathrm{~K}$ is pursued. For lower CCT, the blue spectral region will only have a minor influence on the color rendering. To account for the green and red spectral region, standard broadband phosphors were selected for this: $\mathrm{SrSi}_{2} \mathrm{O}_{2} \mathrm{~N}_{2}: \mathrm{Eu}^{2+}$ and $\mathrm{Sr}_{2} \mathrm{Si}_{5} \mathrm{~N}_{8}: \mathrm{Eu}^{2+}$, a typical combination which is known to yield white light of good color quality and color rendering when combined with a blue pumping diode [6,40].

For the blue component, a gaussian spectral shape was taken, serving as an approximation to the spectrum of a blue phosphor in a UV-pumped pc-LED or a blue LED in a blue-pumped pc-LED. To examine the influence on the color quality scale (CQS) and luminous efficacy of the radiation (LER), the peak wavelength and width (FWHM) of the blue component were varied. It was opted to study the CQS instead of the CRI, since the former was designed to account for the defects inherent to the definition of the latter.

The relative contributions of the red and green phosphors in the simulated LED were adapted such that a constant CCT of $4000 \mathrm{~K}$ and a limited deviation of the Planck locus $\left(\left|D_{\mathrm{uv}}\right|<0.001\right)$ are obtained for all variants of the blue component. The result of this simulation is displayed in Figure 8. In this figure, the approximate locations of a three-band LED with the $\mathrm{Sr}_{0.25} \mathrm{Ba}_{0.75} \mathrm{Si}_{2} \mathrm{O}_{2} \mathrm{~N}_{2}$ : $\mathrm{Eu}^{2+}$ blue phosphor and a traditional blue diode pumped white LED are indicated. Also the location of a three-band LED with the well-known $\mathrm{BaMgAl}_{10} \mathrm{O}_{17}: \mathrm{Eu}^{2+}$ blue phosphor is indicated. This phosphor is characterized by an emission maximum at $450 \mathrm{~nm}$, a FWHM of $55 \mathrm{~nm}$, internal QE of $90 \%$ and can be efficiently excited between $220 \mathrm{~nm}$ and $380 \mathrm{~nm}$ [41,42]. 

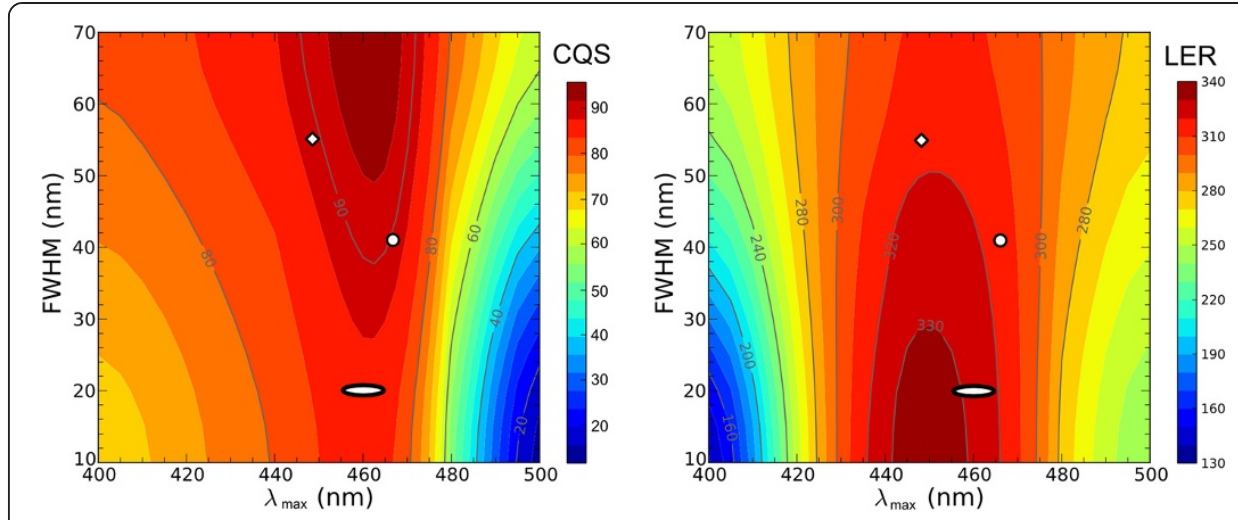

Figure 8 Simulated color quality and luminous efficacy of white LEDs. Influence on color quality scale (CQS, left) and luminous efficacy of radiation (LER, right) of the spectral shape of the blue component in a three-band LED. The approximate location of the $\mathrm{Sr}_{0.25} \mathrm{Ba}_{0.75} \mathrm{Si}_{2} \mathrm{O}_{2} \mathrm{~N}_{2}: \mathrm{Eu}^{2+}$ phosphor is indicated by a circle, the location of the standard blue phosphor $\mathrm{BaMgAl}_{10} \mathrm{O}_{17}$ : $\mathrm{Eu}^{2+}$ is indicated by a diamond and the locations of blue pumping LEDs are indicated by the oval.

It can be seen that it is possible to improve the color quality (CQS) by replacing the blue pumping LED by a UV pumping LED and a blue phosphor. However, the improvement is rather limited because good color quality can already be achieved in the traditional way with a pumping LED of $455 \mathrm{~nm}$. The increase in CQS (from a value of 87 to 89), is at the expense of a decrease in luminous efficacy (315 lm/W instead of $331 \mathrm{~lm} / \mathrm{W})$. Higher color qualities can be achieved if blue phosphors with a broader emission spectrum are used (CQS up to 95 for a phosphor with FWHM $\geq 60 \mathrm{~nm}$ ).

To illustrate this, the spectra of three simulated white LEDs are displayed in Figure 9. As one can see, the cyan gap between the blue pumping LED and the green phosphor can be bridged by using a blue phosphor instead of a blue pumping LED. The highest CQS can be achieved by using a blue phosphor which is significantly broader (FWHM of $65 \mathrm{~nm}$, peaking at $460 \mathrm{~nm}$ ) than the described $\mathrm{Sr}_{0.25} \mathrm{Ba}_{0.75} \mathrm{Si}_{2} \mathrm{O}_{2} \mathrm{~N}_{2}: \mathrm{Eu}^{2+}$ phosphor. In

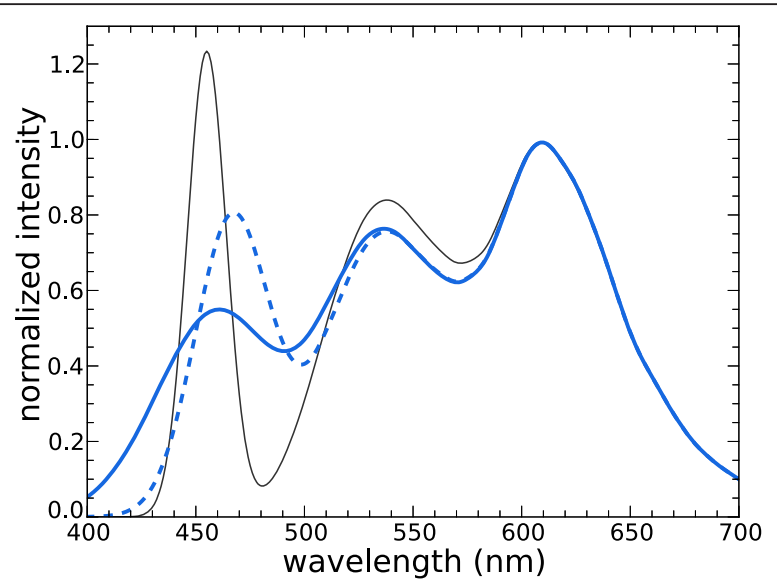

Figure 9 Simulated LED spectra. White LED spectra from simulations. Blue LED pumped (455 nm peak wavelength, thin solid line), UV pumped with a narrow band blue phosphor (467 nm peak wavelength, $40 \mathrm{~nm}$ FWHM, dotted line) and UV pumped with a broad band blue phosphor (460 nm peak wavelength, $65 \mathrm{~nm}$ FWHM, thick solid line). 
this case, a CQS of 96 can be achieved. The LER is $314 \mathrm{~lm} / \mathrm{W}$, which is comparable with the LER of the white LED when the narrow blue phosphor is used.

However, if a blue phosphor is used instead of a blue pumping LED, the phosphor mix needs to be pumped by a UV LED. Because of this, the Stokes shifts will be significantly higher, especially for the red and green phosphors. This will have a severe impact on the overall electrical to optical power conversion efficiency $\left(\eta_{\mathrm{e}-\mathrm{o}}\right)$, the so-called wallplug efficiency $[2,6]$ :

$$
\eta_{\mathrm{e}-\mathrm{o}}=\frac{P_{\mathrm{opt}}}{P_{\mathrm{el}}}=\eta_{\mathrm{LED}} \eta_{\mathrm{extr}}\left(f_{0}+\sum_{i=1}^{N} f_{i} \eta_{\mathrm{int}, i} \frac{\int I_{i}(E) E \mathrm{~d} E / \int I_{i}(E) \mathrm{d} E}{\int I_{\mathrm{LED}}(E) E \mathrm{~d} E / \int I_{\mathrm{LED}}(E) \mathrm{d} E}\right)
$$

In this formula, $\eta_{\mathrm{LED}}$ and $\eta_{\text {extr }}$ represent the electrical to optical power conversion efficiency of the pumping LED and the extraction efficiency of the LED package respectively. $\mathrm{N}$ phosphors are used with relative weights $f_{i}\left(\right.$ with $\left.\sum_{i=1}^{N} f_{i}=1\right)$, internal quantum efficiencies $\eta_{\text {int, } i}$ and spectra $I_{i}(E) . f_{0}$ is the fraction of the spectrum of the pumping LED which is not absorbed by the phosphors. For UV pumping LEDs, $f_{0}$ is ideally 0 . The ratios in equation 5 are called the quantum deficits, originating from the Stokes shifts of the phosphors.

The term between brackets can be calculated for the spectra of the simulated LEDs. Internal quantum efficiencies of $90 \%$ were assumed for all phosphors. This yields a wall-plug efficiency of

$$
\eta_{\mathrm{e}-\mathrm{o}}=0.83 \eta_{\mathrm{LED}} \eta_{\mathrm{extr}}
$$

for the traditional blue pumped white LED and

$$
\eta_{\mathrm{e}-\mathrm{o}}=0.66 \eta_{\mathrm{LED}} \eta_{\text {extr }}
$$

for a $400 \mathrm{~nm}$ pumped white LED with three phosphors. If the pumping LED has a peak wavelength of $370 \mathrm{~nm}$, this becomes:

$$
\eta_{\mathrm{e}-\mathrm{o}}=0.61 \eta_{\mathrm{LED}} \eta_{\mathrm{extr}}
$$

Given the similar external quantum efficiencies of $\operatorname{In}_{1-x} \mathrm{Ga}_{x} \mathrm{~N}$ LEDs $\left(\eta_{\mathrm{LED}}\right)$ in the blue and UV spectral region, there is no possibility to overcome the efficiency difference of at least 20\% between blue and UV LED pumped white LEDs [43].

Because of the decrease in luminous efficacy and wall-plug efficiency while the color quality improves only slightly, it is very unlikely that relatively narrow band blue phosphors will be used in future high color quality LEDs for lighting. For devices with high color quality, whether expressed in CQS or CRI, much broader emission bands are to some extent beneficial.

For certain display or projection applications, based on violet laser excitation, blue phosphors with a narrow emission spectrum such as $\mathrm{Sr}_{0.25} \mathrm{Ba}_{0.75} \mathrm{Si}_{2} \mathrm{O}_{2} \mathrm{~N}_{2}: \mathrm{Eu}^{2+}$ are interesting. In this case, color rendering is irrelevant and saturated colors, corresponding with narrow emission bands are compulsory to achieve a large color gamut for the display [44]. 


\section{Conclusions}

In this work, a complete characterization of the luminescence of a recently reported phosphor in the oxonitridosilicate family is given. The blue emitting material with stoichiometry $\mathrm{Sr}_{0.25} \mathrm{Ba}_{0.75} \mathrm{Si}_{2} \mathrm{O}_{2} \mathrm{~N}_{2}: \mathrm{Eu}^{2+}$ is characterized by broadband emission peaking at $467 \mathrm{~nm}$ at room temperature and a good thermal stability of both the emission intensity and color. An additional weak yellow emission band was observed. The currently obtained internal quantum efficiency of $41 \%$ is too low to allow this phosphor to be used in applications. Nevertheless, this might be improved by an optimization of the synthesis procedure. The phosphor was found to be chemically stable. As a conclusion of this feasibility study, this blue oxonitridosilicate can be suitable for the use in applications if the quantum efficiency can be improved.

Additionally, the microscopic structure of this phosphor was studied. It turned out that no grains with a pure yellow emission could be found, the blue emission is everywhere dominant. The majority of the powder particles do however only emit blue light.

Finally, the potential of blue phosphors to improve the color quality of white LEDs for lighting was investigated because this is often quoted as motivation to study blue phosphors. It was found that only a minor improvement of color quality can be achieved by using a saturated blue phosphor such as the oxonitridosilicate which is subject of this paper, or the $\mathrm{BaMgAl}_{10} \mathrm{O}_{17}: \mathrm{Eu}^{2+}$ phosphor. This increase in color quality is at the expense of a decrease in luminous efficacy and overall electrical-to-optical conversion efficiency of the LED, leading to the conclusion that only the use of blue phosphors with a significant broader emission band (FWHM $\geq 60 \mathrm{~nm}$ ) is justifiable to produce LEDs with very high color quality (CQS > 90). Narrow band phosphors with a saturated blue color are however useful in case of projection or display applications based on conversion of near-UV light, e.g. in the case of laser diode excitation.

Competing interests

The authors declare that they have no competing interests.

\section{Authors' contribution}

$J B$ carried out the synthesis and thermal quenching measurements. JJJ performed the luminescence characterization and the spectral modeling. PFS acquired and processed the SEM-CL data. All authors contributed to the drafting of the manuscript. All read and approved the final manuscript.

\section{Acknowledgements}

This work is financially supported by the agency for Innovation by Science and Technology (IWT) and BOF-UGent. The authors would like to acknowledge Olivier Janssens, Tareq Ahmad and Marlies Decraene for the assistance in the experimental work.

Received: 28 February 2014 Accepted: 5 May 2014

Published: 19 May 2014

\section{References}

1. Krames MR, Shchekin OB, Mueller-Mach R, Mueller GO, Zhou L, Harbers G, Craford MG: Status and future of high-power light-emitting diodes for solid-state lighting. J Display Technol 2007, 3:160-175.

2. Schubert EF: Diode, second edition. Cambridge Universtiy Press; 2006.

3. Hu YS, Zhuang WD, Ye HQ, Zhang SS, Fang Y, Huang XW: Preparation and luminescent properties of $\left(\mathrm{Ca}_{1-x}, \mathrm{Sr}_{x}\right) \mathrm{S}: \mathrm{Eu}^{2+}$ red-emitting phosphor for white LED. J Lumin 2005, 111:139-145.

4. Xie R-J, Hirosaki N, Takeda T, Suehiro T: On the performance enhancement of nitride phosphors as spectral conversion materials in solid state lighting. ECS J Solid State Sci Technol 2013, 2:R3031-R3040.

5. Li YQ, van Steen JEJ, van Krevel JWH, Botty G, Delsing ACA, DiSalvo FJ, de With G, Hintzen HT: Luminescence properties of red-emitting $\mathrm{M}_{2} \mathrm{Si}_{5} \mathrm{~N}_{8}: \mathrm{Eu}^{2+}(\mathrm{M}=\mathrm{Ca}$, Sr, Ba) LED conversion phosphors. J Alloy Compd 2006, 417:273-279.

6. Smet PF, Parmentier AB, Poelman D: Selecting conversion phosphors for white light-emitting diodes. J Electrochem Soc 2011, 158:R37-R54.

7. Bachmann V, Ronda C, Oeckler O, Schnick W, Meijerink A: Color point tuning for $(\mathrm{Sr}, \mathrm{Ca}, \mathrm{Ba}) \mathrm{Si}_{2} \mathrm{O}_{2} \mathrm{~N}_{2}: \mathrm{Eu}^{2+}$ for white light LEDs. Chem Mater 2009, 21:316-325. 
8. Li YQ, Delsing ACA, de With $G$, Hintzen $H T$ : Luminescence properties of Eu ${ }^{2+}$-activated alkaline-earth siliconoxynitride $\mathrm{MSi}_{2} \mathrm{O}_{2-\delta} \mathrm{N}_{2+2 / 3 \delta}(\mathrm{M}=\mathrm{Ca}$, $\mathrm{Sr}, \mathrm{Ba})$ : a promising class of novel LED conversion phosphors. Chem Mater 2005, 17:3242-3248.

9. Xie R-J, Hintzen HT: Optical properties of (Oxy)nitride materials: a review. J Am Ceram Soc 2013, 96:665-687.

10. Botterman J, Van den Eeckhout K, Bos AJJ, Dorenbos P, Smet PF: Persistent luminescence in $\mathrm{MSi}_{2} \mathrm{O}_{2} \mathrm{~N}_{2}: \mathrm{Eu}$ phosphors. Opt Mater Express 2012, 2:341-349.

11. Bachmann V, Justel T, Meijerink A, Ronda C, Schmidt PJ: Luminescence properties of $\mathrm{SrSi}_{2} \mathrm{O}_{2} \mathrm{~N}_{2}$ doped with divalent rare earth ions. J Lumin 2006, 121:441-449.

12. Cho IH, Anoop G, Suh DW, Lee SJ, Yoo JS: On the stability and reliability of $\mathrm{Sr}_{1-x} \mathrm{Ba}_{x} \mathrm{Si}_{2} \mathrm{O}_{2} \mathrm{~N}_{2}: \mathrm{Eu}^{2+}$ phosphors for white LED applications. Opt Mater Express 2012, 2:1292-1305.

13. Song XF, He H, Fu RL, Wang DL, Zhao XR, Pan ZW: Photoluminescent properties of $\mathrm{SrSi}_{2} \mathrm{O}_{2} \mathrm{~N}_{2}: \mathrm{Eu}^{2+}$ phosphor: concentration related quenching and red shift behaviour. J Phys Appl Phys 2009, 42:065409.

14. Seibald M, Rosenthal T, Oeckler O, Schnick W: Highly efficient pc-LED Phosphors $\mathrm{Sr}_{1-x} \mathrm{Ba}_{x} \mathrm{Si}_{2} \mathrm{O}_{2} \mathrm{~N}_{2}: \mathrm{Eu}^{2+}(0 \leq x \leq 1)-$ crystal structures and luminescence properties revisited. Crit Rev Solid State Mater Sci 2014, 39:215-229.

15. Hoppe HA, Stadler F, Oeckler O, Schnick W: $\mathrm{Ca}\left[\mathrm{Si}_{2} \mathrm{O}_{2} \mathrm{~N}_{2}\right]$ - a novel layer silicate. Angew Chem Int Ed 2004, 43:5540-5542.

16. Oeckler O, Stadler F, Rosenthal T, Schnick W: Real structure of $\mathrm{SrSi}_{2} \mathrm{O}_{2} \mathrm{~N}_{2}$. Solid State Sci 2007, 9:205-212.

17. Kechele JA, Oeckler $\mathrm{O}$, Stadler $\mathrm{F}$, Schnick W: Structure elucidation of $\mathrm{BaSi}_{2} \mathrm{O}_{2} \mathrm{~N}_{2}$ - a host lattice for rare-earth doped luminescent materials in phosphor-converted (pc)-LEDs. Solid State Sci 2009, 11:537-543.

18. Seibald M, Rosenthal T, Oeckler O, Maak C, Tücks A, Schmidt PJ, Wiechert D, Schnick W: New polymorph of the highly efficient LED-phosphor $\mathrm{SrSi}_{2} \mathrm{O}_{2} \mathrm{~N}_{2}: \mathrm{Eu}^{2+}$ - polytypism of a layered oxonitridosilicate. Chem Mater 2013, 25:1852-1857.

19. Seibald M, Rosenthal T, Oeckler O, Fahrnbauer F, Tucks A, Schmidt PJ, Schnick W: Unexpected luminescence properties of $\mathrm{Sr}_{0.25} \mathrm{Ba}_{0.75} \mathrm{Si}_{2} \mathrm{O}_{2} \mathrm{~N}_{2}: \mathrm{Eu}^{2+}$ - a narrow blue emitting oxonitridosilicate with cation ordering. Chem Eur J 2012, 18:13446-13452.

20. Botterman J, Van den Eeckhout K, De Baere I, Poelman D, Smet PF: Mechanoluminescence in $\mathrm{BaSi}_{2} \mathrm{O}_{2} \mathrm{~N}_{2}$ :Eu. Acto Mater 2012, 60:5494-5500.

21. Stadler F, Oeckler O, Hoppe HA, Moller MH, Pottgen R, Mosel BD, Schmidt P, Duppel V, Simon A, Schnick W: Crystal structure, physical properties and HRTEM investigation of the new oxonitridosilicate EuSi $\mathrm{O}_{2} \mathrm{~N}_{2}$. Chem Eur J 2006, 12:6984-6990.

22. Li YQ, Ramanujachary KV, Lofland SE, de With G, Hintzen $\mathrm{HT}$ : Optical and magnetic properties of $\mathrm{EuSi}_{2} \mathrm{O}_{2} \mathrm{~N}_{2}$. J Mater Res 2006, 21:396-401.

23. Zhang L, Xu C-N, Yamada H: Strong mechanoluminescence from oxynitridosilicate phosphors. IOP Conf Ser Mater Sci Eng 2011, 18:212001.

24. Yun $\mathrm{BG}$, Miyamoto $\mathrm{Y}$, Yamamoto H: Luminescence properties of $\left(\mathrm{Sr}_{1-u} \mathrm{Ba}_{u}\right) \mathrm{Si}_{2} \mathrm{O}_{2} \mathrm{~N}_{2}: \mathrm{Eu}^{2+}$, yellow or orange phosphors for white LEDs, synthesized with $\left(\mathrm{Sr}_{1-u} \mathrm{Ba}_{u}\right)_{2} \mathrm{SiO}_{4}: \mathrm{Eu}^{2+}$ as a precursor. J Electrochem Soc 2007, 154:J320-J325.

25. Liu LH, Xie R-J, Zhang CN, Hirosaki N: Role of fluxes in optimizing the optical properties of $\mathrm{Sr}_{0.95} \mathrm{Si}_{2} \mathrm{O}_{2} \mathrm{~N}_{2}: 0.05 \mathrm{Eu}^{2+}$ green-emitting phosphor. Materials 2013, 6:2862-2872

26. Stadler F, Kraut R, Oeckler O, Schmid S, Schnick W: Synthesis, crystal structure and solid-state NMR spectroscopic investigation of the oxonitridosilicate $\mathrm{BaSi}_{6} \mathrm{~N}_{8} \mathrm{O}$. Z Anorg Allg Chem 2005, 631:1773-1778

27. Braun C, Seibald M, Borger SL, Oeckler O, Boyko TD, Moewes A, Miehe G, Tucks A, Schnick W: Material properties and structural characterization of $\mathrm{M}_{3} \mathrm{Si}_{6} \mathrm{O}_{12} \mathrm{~N}_{2}: \mathrm{Eu}^{2+}(\mathrm{M}=\mathrm{Ba}, \mathrm{Sr})$ - a comprehensive study on a promising green phosphor for pc-LEDs. Chem Eur J 2010, 16:9646-9657.

28. Stadler $\mathrm{F}$, Schnick W: The new layer-silicates $\mathrm{Ba}_{3} \mathrm{Si}_{6} \mathrm{O}_{9} \mathrm{~N}_{4}$ and $\mathrm{Eu}_{3} \mathrm{Si}_{6} \mathrm{O}_{9} \mathrm{~N}_{4}$. Z Anorg Allg Chem 2006, 632:949-954.

29. Xie R-J, Hirosaki N, Li YQ, Takeda T: Photoluminescence of $\left(\mathrm{Ba}_{1-x} \mathrm{Eu}_{x}\right) \mathrm{Si}_{6} \mathrm{~N}_{8} \mathrm{O}(0.005 \leq \mathrm{x} \leq 0.2)$ phosphors. J Lumin 2010, 130:266-269

30. Mikami M, Shimooka S, Uheda K, Imura $\mathrm{H}$, Kijima N: New green phosphor $\mathrm{Ba}_{3} \mathrm{Si}_{6} \mathrm{O}_{12} \mathrm{~N}_{2}$ :Eu for white LED: crystal structure and optical properties. Key Eng Mater 2009, 403:11-14.

31. Seibald M, Oeckler O, Celinski VR, Schmidt PJ, Tucks A, Schnick W: Real structure and diffuse scattering of $\mathrm{Sr}_{0.5} \mathrm{Ba}_{0.5} \mathrm{Si}_{2} \mathrm{O}_{2} \mathrm{~N}_{2}: \mathrm{Eu}^{2+}$ - a highly efficient yellow phosphor for pc-LEDs. Solid State Sci 2011, 13:1769-1778

32. Bachmann V, Ronda C, Meijerink A: Temperature quenching of yellow $\mathrm{Ce}^{3+}$ luminescence in YAG:Ce. Chem Mater 2009, 21:2077-2084.

33. Smet PF, Botterman J, Parmentier AB, Poelman D: Thermal quenching at the microscopic level in multi-phase thiosilicate phosphors. Opt Mater 2013, 35:1970-1975.

34. Dorenbos P: Energy of the first $4 f^{7} \rightarrow 4 f^{6} 5 d$ transition of Eü ${ }^{2+}$ in inorganic compounds. J Lumin 2003, 104:239-260

35. Dorenbos P: Anomalous luminescence of $\mathrm{Eu}^{2+}$ and $\mathrm{Yb}^{2+}$ in inorganic compounds. J Phys Condens Matter 2003, 15:2645-2665.

36. Poelman D, Smet PF: Time resolved microscopic cathodoluminescence spectroscopy for phosphor research. Phys B Condens Matter 2014, 439:35-40.

37. Poort SHM, Meyerink A, Blasse G: Lifetime measurements in $\mathrm{Eu}^{2+}$-doped host lattices. J Phys Chem Solid 1997, 58:1451-1456.

38. Setlur AA, Shiang JJ, Happek U: $\mathrm{Eu}^{2+}-\mathrm{Mn}^{2+}$ phosphor saturation in $5 \mathrm{~mm}$ light emitting diode camps. Appl Phys Lett 2008, 92:081104.

39. Davis W, Ohno Y: Color quality scale. Opt Eng 2010, 49:033602.

40. Mueller-Mach R, Mueller G, Krames MR, Hoppe HA, Stadler F, Schnick W, Juestel T, Schmidt P: Highly efficient all-nitride phosphor-converted white light emitting diode. Phys Status Solidi a-Appl Mater Sci 2005, 202:1727-1732.

41. Justel T, Bechtel H, Mayr W, Wiechert DU: Blue emitting BaMgAl ${ }_{10} \mathrm{O}_{17}$ :Eu with a blue body color. J Lumin 2003, 104:137-143. 
42. Mishra KC, Raukas M, Marking G, Chen P, Boolchand P: Investigation of fluorescence degradation mechanism of hydrated $\mathrm{BaMgAl}_{10} \mathrm{O}_{17}: \mathrm{Eu}^{2+}$ phosphor. J Electrochem Soc 2005, 152:H183-H190.

43. Crawford MH: LEDs for solid-state lighting: performance challenges and recent advances. IEEE J Sel Top Quant Electron 2009, 15:1028-1040.

44. Xie R-J, Hirosaki N, Takeda T: Wide color gamut backlight for liquid crystal displays using three-band phosphor-converted white light-emitting diodes. Appl Phys Express 2009, 2:022401.

doi:10.1186/2196-1107-1-6

Cite this article as: Joos et al: Evaluating the use of blue phosphors in white LEDs: the case of $\mathrm{Sr}_{0.25} \mathrm{Ba}_{0.75} \mathrm{Si}_{2} \mathrm{O}_{2} \mathrm{~N}_{2}: \mathrm{Eu}^{2+}$. Journal of Solid State Lighting 2014 1:6.

Submit your manuscript to a SpringerOpen ${ }^{\circ}$ journal and benefit from:

- Convenient online submission

- Rigorous peer review

- Immediate publication on acceptance

- Open access: articles freely available online

- High visibility within the field

- Retaining the copyright to your article

Submit your next manuscript at $>$ springeropen.com 